\title{
Microfibers in Mytilus species (Mollusca, Bivalvia) from Southern California Harbors, Beaches, and Supermarkets
}

\author{
Chloe Mankin* \& Andrea Huvard \\ Department of Biology, California Lutheran University, Thousand Oaks, CA \\ https:// doi.org/10.33697/ ajur.2020.019 \\ Student: cmankin@callutheran.edu* \\ Mentor:buvard@callutheran.edu
}

\begin{abstract}
Plastic microfibers are an emerging threat to terrestrial and aquatic habitats worldwide. They are equivalent in size to planktonic organisms, making them available to a range of invertebrates. Bivalve mollusks can ingest and accumulate plastics via digestion and adherence to soft tissue. We determined the frequency and characteristics of microfiber pollution from wild Mytilus californianus and farmed Mytilus edulis populations that were collected from southern California harbors, beaches, and supermarkets ( $\mathrm{n}=4$ per site). Mussel organic matter was dissected using $30 \% \mathrm{H}_{2} \mathrm{O}_{2}$. After adding a saline solution to separate the fibers, the liquid was filtered by vacuum filtration. The remaining fibers were examined with a magnification of $1 \sim 8 x$. In this short-term survey, the abundance of microfibers by sample and by shell length showed a significant difference between the harbor and beach sites. However, there was not a significant difference between the wild and farmed mussels examined. This study revealed widespread microfiber pollution and uptake by mussels in these locations and reinforces how bivalves can be used as a bioindicator of microfiber pollution.
\end{abstract}

\section{KEYWORDS}

Microplastic; Microfiber; Mytilus; Biomonitoring; Bivalvia; Seafood; Human Health

\section{INTRODUCTION}

The large-scale production and use of plastic only dates back to 1950. As of 2015, approximately 6,300 million metric tons (Mt) of plastic waste has been produced with $79 \%$ accumulating in landfills or the natural environment. ${ }^{1}$ This rapid growth in plastic production has led to an abundance of discarded plastics worldwide. Because plastics are manufactured to be durable and nonbiodegradable, they are persistent in the natural environment and thus can negatively influence organisms at both the macro- and micro-level. ${ }^{2}$ For example, ingestion of large inorganic plastics, defined as macroplastics ( $\left.>5 \mathrm{~mm}\right)$, can block an animal's digestive tract, leading to starvation or digestive tract obstruction. ${ }^{3}$

\begin{abstract}
Although the effects of macroplastics are well documented, ${ }^{3}$ microplastics are of growing concern in the marine environment due to their high abundances in the water column, ocean sediments, and marine organisms. Microplastics, typically defined as less than $5 \mathrm{~mm}$ in diameter, are caused by the degradation of macroplastics, by wave action, photodegradation, or other environmental factors. ${ }^{3}$ Microplastics are equivalent in size to planktonic organisms and other food particles that organisms ingest, making them available to a range of marine organisms. Their size allows microplastics to move readily through marine trophic systems. ${ }^{4}$ Numerous laboratory trials have investigated the ingestion and accumulation of microplastics within marine organisms. ${ }^{2}$, 5,6 Although no significant detrimental effects have been observed, the abundance of microplastics in the environment raises toxicity concerns. ${ }^{5}$ Their large surface area-to-volume ratio causes microplastics to concentrate high levels of persistent organic pollutants (POPs). Whether these high levels are physiologically meaningful is a point of concern and a need for research. In addition, organic pollutants may have the potential to act as a chemical inhibitor within living organisms that may bioaccumulate within food webs. ${ }^{3}$
\end{abstract}

Microfibers, a subcategory of microplastics, are a pollutant caused by the degradation of synthetic fibers. ${ }^{7}$ During the machine washing of polyester, polypropylene, acrylic, nylon, or other synthetic garments, large numbers of microfibers are discharged into wastewater with each garment releasing up to $10^{7}$ fibers per wash. ${ }^{8}$ The fibers enter the environment directly through septic systems and reused water, or indirectly through wastewater treatment plants. ${ }^{9}, 10$ As a consequence, synthetic fibers are the most abundant type of microplastic in the marine environment. ${ }^{8}$

We studied the uptake and retention of microfibers by examining two species of the cosmopolitan marine mussel genus Mytilus: (M. californianus and $M$. edulis). These species are widespread and a vital food source for a range of organisms, including humans. 
Mollusks have been used as bioindicators of marine pollution in multiple studies. ${ }^{11,12,13}$ Mussels are sedentary suspension feeders that ingest nutrients by straining particulate matter from the water column. They filter water over their gills where they capture planktonic organic material and pass it to their mouths. Mollusks have minimal ability to excrete pollutants through their organs and tissues, causing them to have a greater ability to bioaccumulate contaminants than other organisms. ${ }^{14}$ Their high sensitivity to pollutants enables their use as an environmental early warning system. Thus, the large number of microfibers entering the Pacific coastal area daily subject the mussels to accumulation and retention of the plastics through ingestion, digestion, and adherence. ${ }^{4}$

We conducted a three-month-long survey on microfiber accumulation in wild and commercial Mytilus spp. collected from three types of sampling sites: harbors, beaches and supermarkets. The mussels were collected from four docks located in marine harbors, four rock jetties located at coastal beaches, and four supermarkets located in southern California. The sites were chosen based on their proximity to large sectors of commercial and residential activity. We determined the difference in abundance and characteristics of microfiber pollution in wild $M$. californianus communities and farmed $M$. edulis samples between the three site types. Although Mytilus usually occurs in shallow marine environments, the collection sites differed in terms of substrate, tidal current, and wave action. In addition, the prevalence of wastewater, runoff, and water reuse in residential areas varied between locations. Due to limited wave action and a higher prevalence of wastewater near harbors, we expected the mussels collected in these locations to exhibit an increased intake of microfibers when compared to samples collected near coastal beaches. In literature, reports have found that farmed mussels have significantly higher microplastic concentrations than wild-caught mussels. This is due to farmed mussels often being cultured in coastal areas and grown on polypropylene plastic lines. ${ }^{14}$ Due to these factors, we expected the farmed mussels to have an increased intake of microfibers when compared to the wild samples.

\section{METHODS AND PROCEDURES}

Sample collection

Mussels were collected randomly from four harbors, four beaches, and four supermarkets throughout southern California

(Figure 1). A Review of California Mussel (Mytilus californianus), Fisheries Biology and Fisheries Program was used as a reference for species identification. ${ }^{15}$ M. californianus was distinguished from other organisms by its coarse thick shell with radial ribs, bluish-colored outer layer, bright orange meat, blunt shell shape, and size 130 150 mm. The harbor mussels were collected from Ventura, Newport Beach, Santa Barbara, and Morro Bay. The beach mussels were collected from Ventura, Mission Beach, Oceanside, and Avila Beach. M. edulis was collected from supermarkets due to its intensive commercial and aquaculture use. The Marine Species Identification Portal was reference. ${ }^{16}$ The mussel was distinguished by its solid, triangular shell shape, dark purplish-blue outer layer, and size 50 100 mm. The mussels were farm-raised, originating in Washington and California. These organisms were collected from Whole Foods, Gelson's Market, Vons, and Costco located in Ventura County. Eighteen mussels were collected from each of the twelve sites and transferred to the laboratory. The organisms were then transferred to a filtered, natural seawater tank to allow them to clear their gut for dissection. The mussels ranged in weight from 0.69 to $21.3 \mathrm{~g}$ ww (wet weight) and in length from 1.60 to $12.8 \mathrm{~cm}$

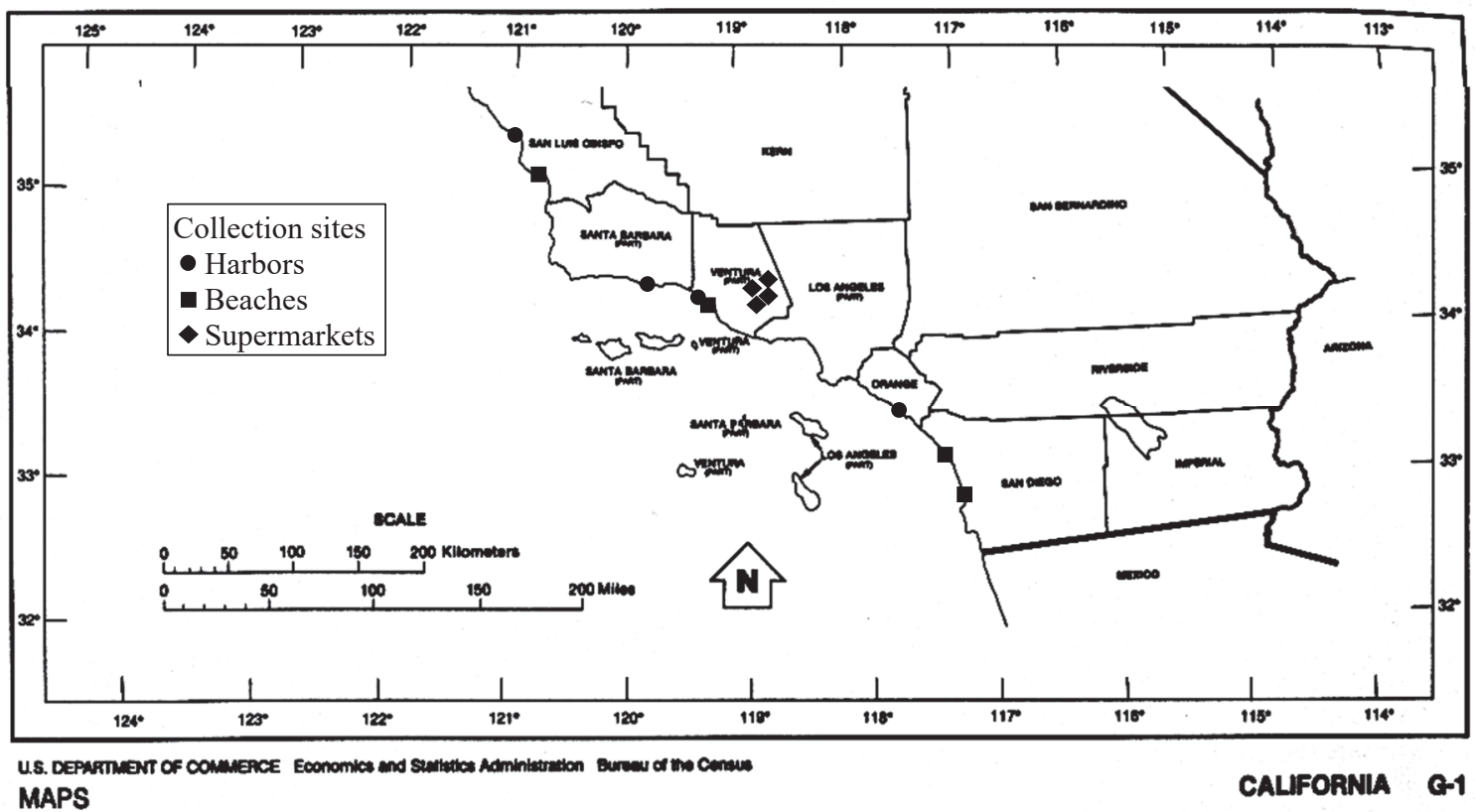

Figure 1. Sampling sites of mussels along the southern California beaches and harbors. Supermarkets were selected due to their proximity to California Lutheran University. 


\section{Minimizing contaminants}

Given the abundance of microfibers in the environment, procedures were followed to minimize contamination during transport or in the lab. To minimize contaminants, all experimental processes described below were completed as quickly as possible.

During mussel dissection, only natural fiber clothing and standard non-plastic equipment were used, such as steel dissecting tools and glass petri dishes. Equipment and processed filter paper samples were placed in sealed containers and stored in a fume hood. Methodological controls, such as blanks, were not used due to limited resources, time, and funding. Although the complete removal of fibers from an environment is impossible, these procedures have shown to minimize contaminants. ${ }^{3}$

\section{Sample preparation}

The weight of the organic matter and shell length of each mussel was recorded using a Vernier caliper and precision balance, respectively. To dissect the mussels, the valves were cut open by inserting a metal scalpel between the two valves on the dorsal side and the anterior adductor muscle. The organic matter of each mussel was then weighed and recorded. The organic matter of two mussels were combined and placed into $500 \mathrm{~mL}$ individual glass bottles. The combined matter was regarded as a sample. Thus, nine samples with a total of 18 mussels were prepared at each site. These replicates were used to measure variation in the experiment and locate outlier results. Four of the mussels were contaminated during the sample preparation process. Therefore, one sample from Newport Harbor and Oceanside Beach were rejected.

Depending on the weight of the organic matter in each bottle, 30 to $70 \mathrm{~mL} 30 \% \mathrm{H}_{2} \mathrm{O}_{2}$ was added to digest the organic matter. ${ }^{4}$ For 24 hours, the beakers were covered with aluminum foil and placed in a water bath incubator at $65^{\circ} \mathrm{C} .17$

After digestion, $100 \mathrm{~mL}$ of $\mathrm{NaCl}$ solution was added to each beaker to separate the microfibers from the dissolved liquid of the organic matter via flotation. ${ }^{6}$ The mixture was left for 24 hours in the water bath incubator. The liquid was filtered by vacuum filtration over a $5 \mu \mathrm{m}$ cellulose nitrate membrane filter. ${ }^{6}$ The filter was placed in a sealed container for further observation under a microscope.

Observation and validation of microfibers

All microfibers on the filter $(n=106)$ were examined, counted, and characterized under a Nikon Stereo Microscope SMZ800N and examined with a magnification of $1 \sim 8 x$. Images were taken using an iPhone camera. We recorded organic matter weight ( $\mathrm{g}$ ), shell length $(\mathrm{cm})$, and fiber color for each sample. No other type of microplastic was analyzed. A visual assessment was used to identify and count the number of microfibers. Approximately 60 minutes were spent examining each filter. Each microfiber was identified by observing the characteristics described in Hidalgo-Ruz et al., 2012.18

\section{Data analysis.}

Statistical analyses were conducted using Excel. A one-way analysis of variance (ANOVA) was used to compare microfiber concentrations from mussels collected at the harbor, beach, and supermarket sites. The average abundance of microfibers per sample, per weight, and per shell length were compared in this analysis. If these tests indicated significant differences, then a Tukey test was used to determine the significant location. In addition, two simple linear regression analyses were used to determine whether weight or shell length is a better predictor of ingested microplastics. Statistical differences were considered significant when $p<0.05$.

\section{RESULTS}

In this study we found a total of 1,038 microfibers in 212 mussels with $99.98 \%$ of the mussels containing microfibers. The most abundant color of microfiber identified was black at $43 \%$, followed by blue at 30\%, transparent at 17\%, and red at 10\%. An example of a blue microfiber is shown in Figure 2a. A pilot study conducted by the author revealed that microfibers occurred on the gill surfaces, stomach area, and intestines of the mussels. An example of a microfiber on a gill is shown in Figure $2 \mathbf{b}$. 


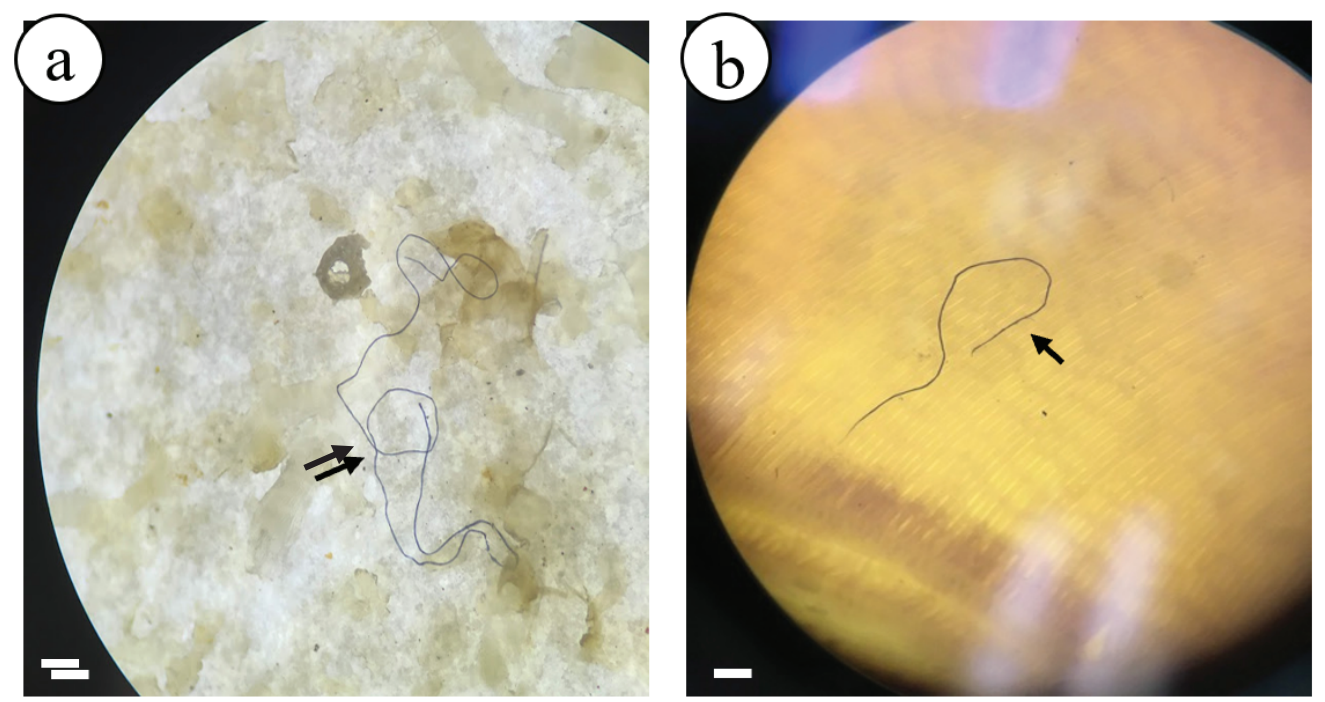

Figure 2. Close-up images of microfiber on filter (a) and on dissected gill of mussel (b). Scale bar $=1 \mathrm{~mm}$.

Microfiber abundance was significantly higher at the harbor sites than at the coastal sites. A one-way analysis of variance showed that the harbor sites were significantly higher in regard to fibers per sample $(p=0.006)$ and per shell length $(p=0.049)$. There was not a significant difference between fibers per weight $(p=0.253)$. A Tukey test indicated that Newport Harbor was significantly higher than the other harbor sites when comparing fibers per sample $\left(p=5.07 \times 10^{-7}\right)$, per weight $(p=$ $\left.5.30 \times 10^{-7}\right)$, and per shell length $\left(p=6.69 \times 10^{-8}\right)$. There was not a significant difference between the wild and farmed samples collected. However, a Tukey test indicated there were significantly more fibers per gram at Gelson's Market than Whole Foods $\left(p=2.00 \times 10^{-3}\right)$. Two simple linear regression analyses revealed that there was no correlation between the number of microfibers and weight $(p=0.235)$ and between the number of microfibers and shell length $(p=0.343)$.

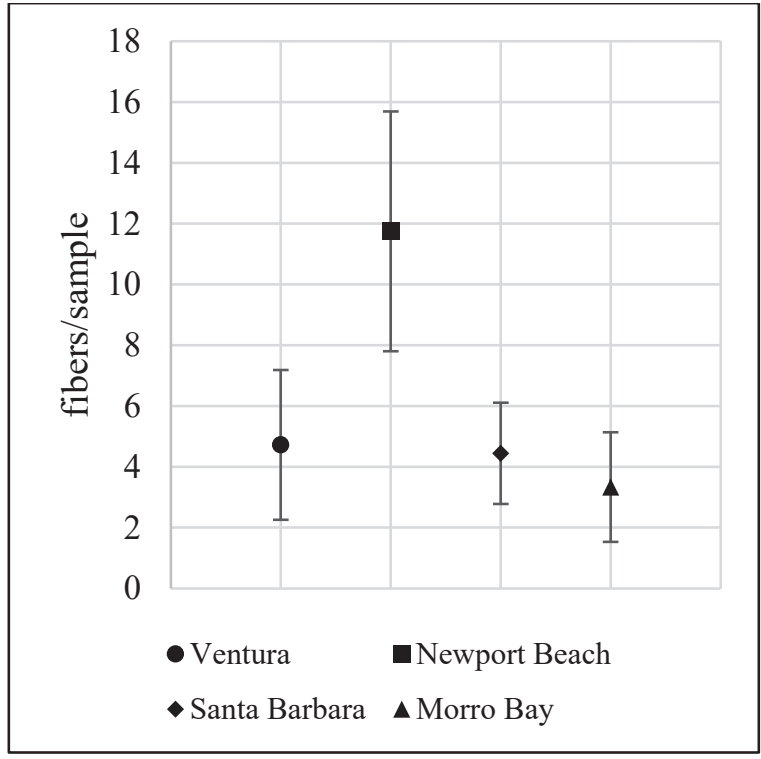

Figure 3a. Mussels collected from harbors.

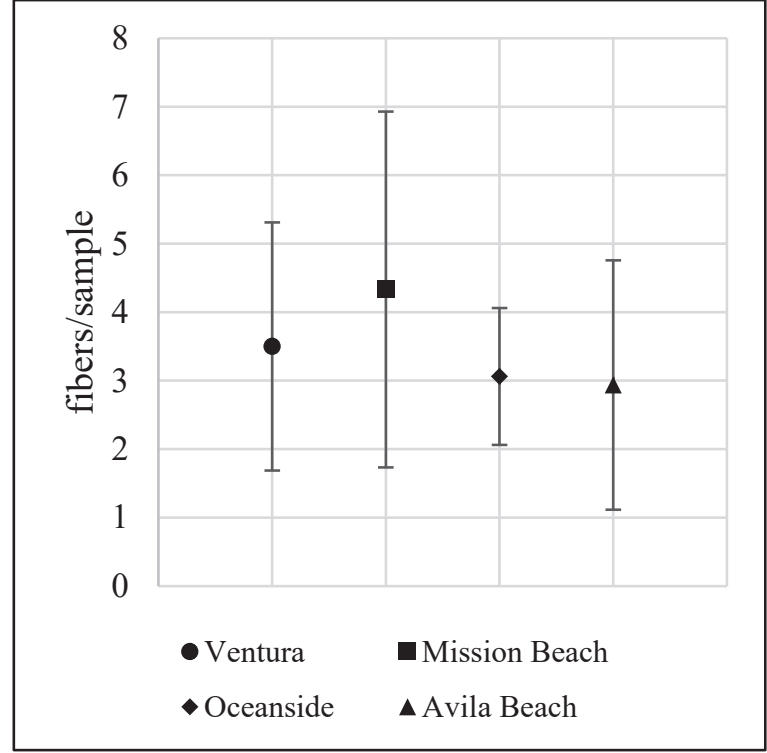

Figure 3b. Mussels collected from beaches. 


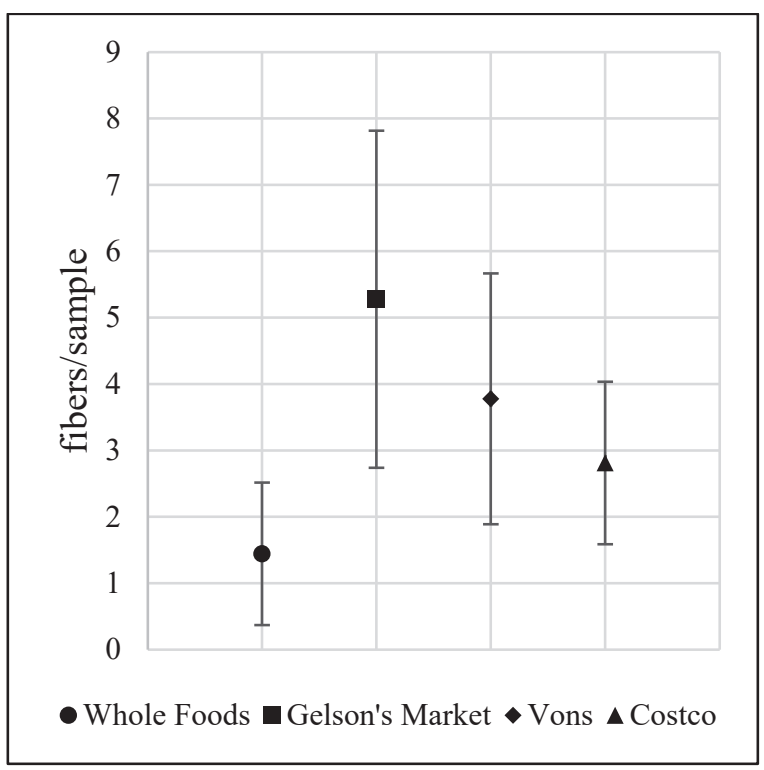

Figure 3c. Mussels collected from supermarkets.

Figure 3. Comparison of the average number of microfibers in wild mussels collected from harbors and beaches, and farmed mussels collected from local supermarkets. Bars represent mean value +/- Standard deviation. Outliers have been removed.

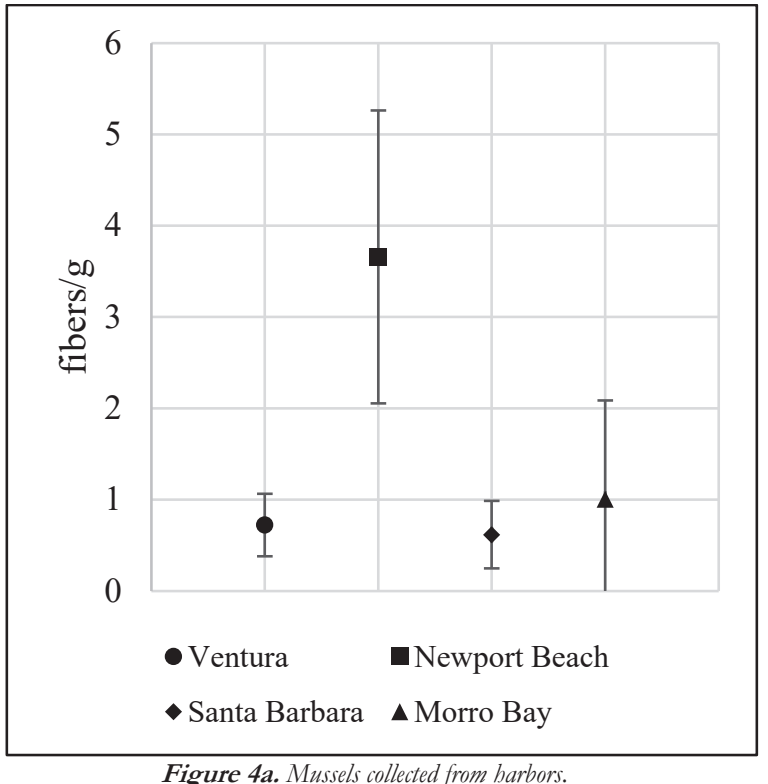

Figure 4a. Mussels collected from barbors.

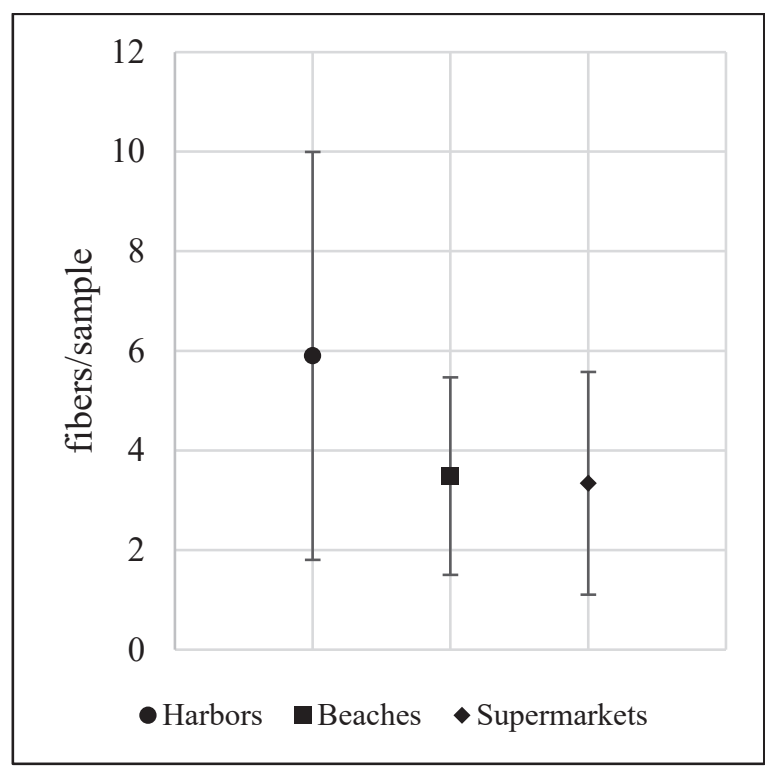

Figure 3d. Mussels collected from the three site types.

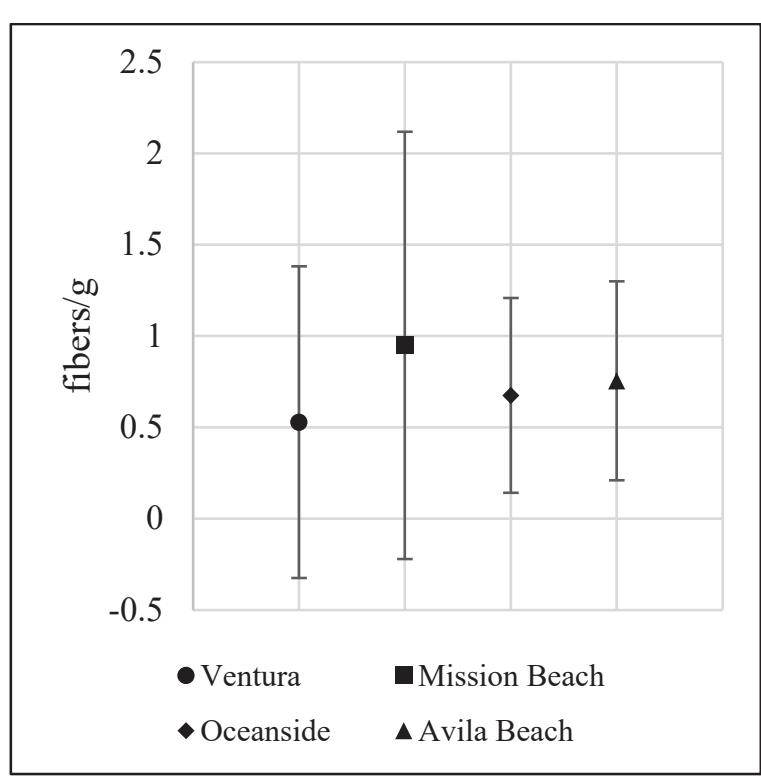

Figure 4b. Mussels collected from beaches. 


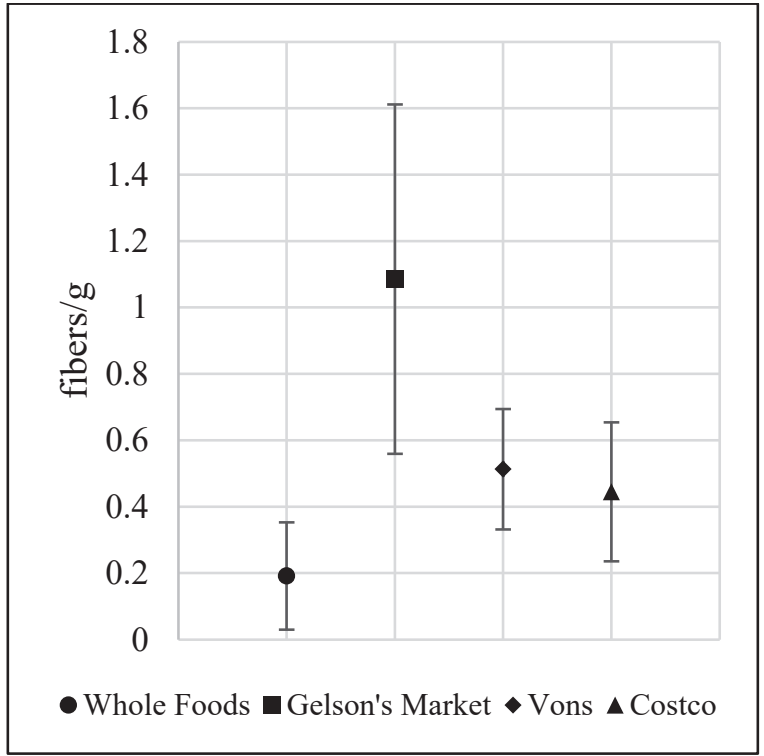

Figure 4c. Mussels collected from supermarkets.

Figure 4. Comparison of the average number of microfibers per weight in wild mussels collected from harbors and beaches, and farmed mussels collected from local supermarkets. Bars represent mean value $+/$ - Standard deviation. Outliers have been removed.
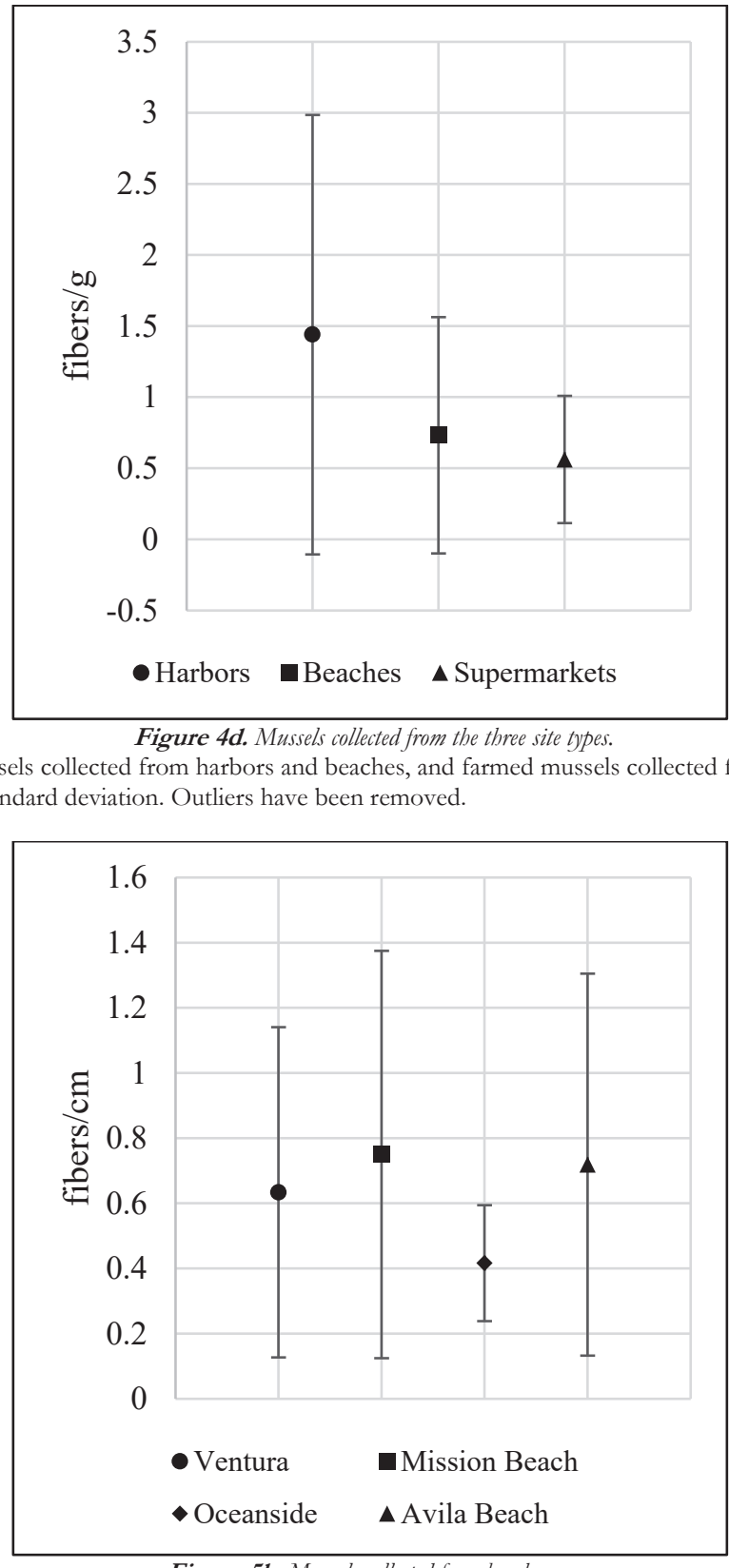

Figure 5b. Mussels collected from beaches. 


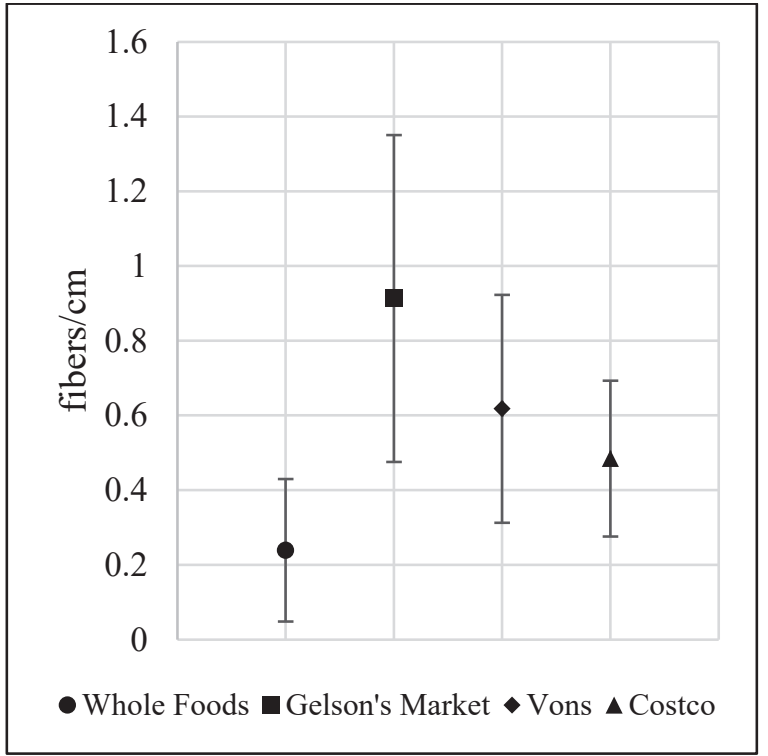

Figure 5c. Mussels collected from supermarkets.

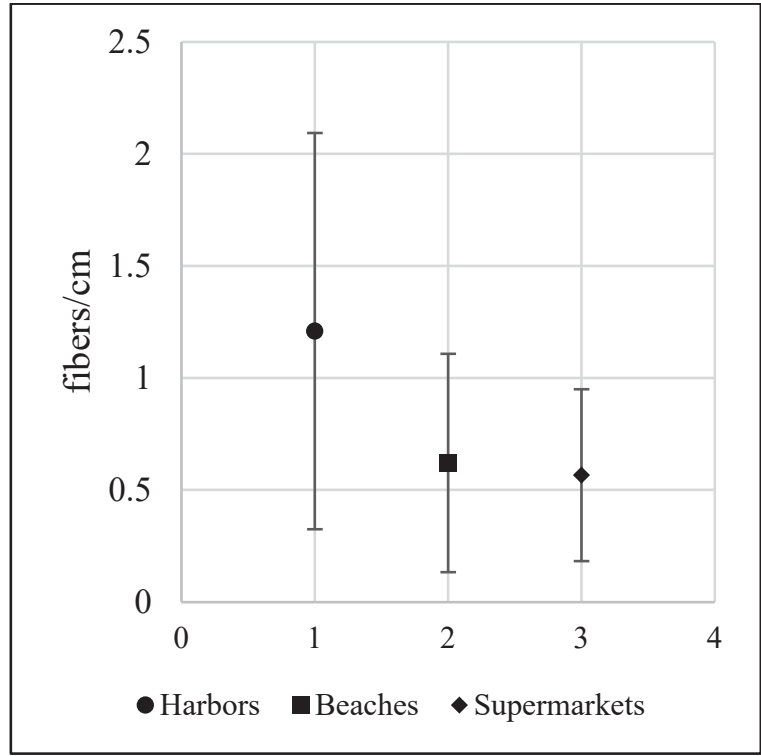

Figure 5 b. Mussels collected from the three site types.

Figure 5. The average number of microfibers per shell length in wild mussels collected from harbors and beaches, and farmed mussels collected from local supermarkets. Bars represent mean value +/- Standard deviation. Outliers have been removed.

The total number of microfibers on each filter was divided by the total weight of organic matter to obtain the number of microfibers per gram of soft tissue and microfibers per centimeter of shell. The number of microfibers varied from 0.0 to 13.5 fibers/sample (Figure 3d), 0.0 to 6.30 fibers/g ww (Figure 4d), and 0.0 to 3.88 fibers/cm (Figure 5d). At the harbor sites, mussels contained on average 6.04 fibers/sample (Figure 3a), 1.38 fibers/g ww (Figure 3b), and 1.21 fibers/cm (Figure 3c). The beach sites contained 3.62 fibers/sample (Figure 4a), 0.55 fibers/g ww (Figure 4b), and 0.762 fibers/cm (Figure 4c). The farmed sites contained 3.21 fibers/sample (Figure 5a), 0.56 fibers/g ww (Figure 5b), and 0.652 fibers/cm (Figure 5c). An outlier was removed from the Costco and Ventura beach sites.

\section{DISCUSSION}

Microfiber pollution was widespread in both wild $M$. californianus and farmed $M$. edulis samples. The abundance of microfibers was significantly higher in the harbor sites (6.04 fibers/sample) than the beach sites (3.62 fibers/sample). There are multiple factors that could have influenced microfiber concentration levels, such as varying marine environments, proximity to nearby human activity, and sources of effluent discharge. ${ }^{19}$ Harbors are known to have higher rates of accumulation than rocky shorelines due to their low energy environments where particles are often deposited as sediment. ${ }^{20}$ Meanwhile, exposed rock jetties are characterized by their high energy environments where particles often remain in suspension.

Bivalves collected near commercial or industrial activity, as well as sheltered bays and harbors, have an increased probability of microfiber uptake. ${ }^{19}$ The harbors and beaches examined were located near large sectors of commercial and residential activity, where the average population is 73,887 people and 83,635 people, respectively. ${ }^{21}$ Due to large population pressures, there are many potential sources of residential and commercial discharge. For example, wastewater often flows directly into coastal bays through routes such as construction debris, grease clogs, root intrusion, and structural failures of pipes. ${ }^{22}$ In Newport Beach, 14 sewer systems failed from 2013 to 2018, spilling at least 6,400 gallons of wastewater into Newport Bay and the open ocean. ${ }^{22}$ When compared to the other sites, the direct discharge of greywater may have significantly increased the number of microfibers in Newport Bay.

We expected the farmed mussels to contain more microfibers than the wild mussels. There was a significant difference between the supermarket and harbor mussels examined, but not between the supermarket and beach mussels. Similar population pressures and environmental factors may have resulted in the insignificance. The supermarket mussels collected from Whole Foods, Gelson's Market, Vons, and Costco were cultivated in Carlsbad, Santa Monica, and Pleasanton, California and Coupeville, Washington, respectively. The microfiber input in these regions, where the average population is approximately 72,383 people, ${ }^{21}$ would be similar to the beach sites examined. The mussels also likely had similar culture conditions to the beach samples. Farmed mussels are often cultured in coastal areas and grown on ropes suspended into the water column. ${ }^{22}$ These mussels feed on algae naturally presented in the seawater and as a result, are exposed to any pollutant in the environment, including microfibers and other anthropogenic particles. ${ }^{23}$ 
The difference in Mytilus species may have also affected the number of microfibers accumulated and retained. Although the organisms are closely related, $M$. californianus is a larger species, usually containing twice as much dry meat as $M$. edulis. ${ }^{24}$ However, there was no correlation between the number of fibers and weight or shell length. This suggests that local pollution has more of an impact than mussel size or species.

The average number of fibers we identified per sample (4.47 fibers/sample) and per gram of organic matter (1.02 fibers/g) was consistent when compared to the amount reported in other studies. For example, 0.26-0.51 fibers/g were identified in De Witte et al., $2014^{5}$ and 2.1-10.5 items/g were identified in Li et al., 2015. ${ }^{17}$ However, concentrations recorded might be overestimated due to the limited contamination prevention protocols completed in this study. This could have a considerable impact on the procedural contamination levels. For example, airborne fibers in the laboratory, water supplies, and hydrogen peroxide could not be ruled out, which might have contaminated the samples. Further work, equipment, and methodological checks are needed to limit contamination, such as procedural blank filters and Tape Lift Screening. ${ }^{23}$ The short duration of the project and the limited data collected may have affected the concentrations of microfibers recorded. Additional data could reveal a significant difference between the wild and farmed samples or an increase or decrease in the concentrations of microfiber contamination in these southern California locations. It could also reveal a correlation between the number of fibers and weight or shell length of the mussels.

Despite for the limitations of this study, microfibers were observed on $99.98 \%$ of the filter examined, indicating widespread microfiber pollution and uptake by mussels in these locations. The presence of microfibers in the visceral mass indicates ingestion of these plastics. In numerous studies, microplastics have caused physical damage to the organism examined.2, 4, 25 For example, microplastics have induced inflammatory responses and decreased lysosomal stability in bivalves, revealing associated stress, a toxicological response, and pathological changes ${ }^{24}$ In addition, the accumulation of microfibers inside the bivalves increases the probability of plastics transferring to higher trophic levels. Field investigations also have shown that microplastic abundance in mussels is correlated to the range of human activity in their surrounding environment. ${ }^{6}$ Thus, microfiber pollution observed in the mussels reflects local levels of contamination in the water and sediment and indicates that bivalves can continued to be used as a bioindicator of marine pollution.

\section{CONCLUSIONS}

As the global demand for plastic increases, the number of organisms ingesting microplastics will too. Microfibers are more ubiquitous than once thought, prevailing in marine environments, the Artic, ${ }^{26}$ and the most isolated areas in the United States, such as national parks and national wilderness areas. ${ }^{27}$

In our oceans, microplastics could detrimentally affect ecosystems and human health, causing demographic and food and prey shifts, taxa specific vulnerability, and hazards to human food. ${ }^{3}$ Seafood consumption represents one of the most common pathways for human microplastic exposure. ${ }^{28}$ Along with the continuous growth of plastic, seafood consumption has more than doubled to over $20 \mathrm{~kg}$ per capita per year in past 50 years. ${ }^{29}$ With this increase in seafood consumption, microfibers may pose more of a threat to food safety.

Although in current literature there is limited data on the toxicity of microplastics in humans, it is likely that microplastics absorb monomers, additives, and POPs, enhancing the toxicity of these plastics. ${ }^{28}$ In addition, preliminary research has demonstrated many concerning impacts microplastics may have on the human body, such as enhancing inflammatory responses and disrupting the gut microbiome. ${ }^{19}$

However, the differences in techniques of isolating and identifying microplastics makes it difficult to compare the levels of pollution between studies. The creation of comprehensive models, along with uniform and more effective methods, should be developed in the future. This could aid in determining the toxicological risk microplastics pose to bivalves, humans, and other organisms consuming these plastics.

\section{ACKNOWLEGMENTS}

The author wants to thank California Lutheran University for providing the opportunity to conduct this research and Swenson Science Summer Research Fellowship for funding the project. She is grateful to Mia LeClerc and Steven Ortez Hernandez for their assistance with the data collection throughout the project, and especially Dr. Andrea Huvard and Dr. Bryan Swig for their support and guidance.

\section{REFERENCES}

1. Geyer, R., Jambeck, J. R., \& Law, K. L. (2017) Production, use, and fate of all plastics ever made. Science Advances, 3(7), e1700782. doi:10.1126/sciadv.1700782 
2. Browne, M. A., Dissanayake, A., Galloway, T. S., Lowe, D. M., \& Thompson, R. C. (2008) Ingested Microscopic Plastic Translocates to the Circulatory System of the Mussel, Mytilus edulis (L.). Environmental Science \& Technology, 42(13), 5026-5031. doi:10.1021/es800249a

3. Taylor, M. L., Gwinnett, C., Robinson, L. F., \& Woodall, L. C. (2016) Plastic microfibre ingestion by deep-sea organisms. Scientific Reports, 6(1). doi:10.1038/ srep33997

4. Kolandhasamy, P., Su, L., Li, J., Qu, X., Jabeen, K., \& Shi, H. (2018) Adherence of microplastics to soft tissue of mussels: A novel way to uptake microplastics beyond ingestion. Science of The Total Environment, 610-611, 635-640. doi:10.1016/j.scitotenv.2017.08.053

5. De Witte, B., Devriese, L., Bekaert, K., Hoffman, S., Vandermeersch, G., Cooreman, K., \& Robbens, J. (2014) Quality assessment of the blue mussel (Mytilus edulis): Comparison between commercial and wild types. Marine Pollution Bulletin, 85(1), 146-155. doi:10.1016/j.marpolbul.2014.06.006

6. Li, J., Qu, X., Su, L., Zhang, W., Yang, D., Kolandhasamy, P. Shi, H. (2016) Microplastics in mussels along the coastal waters of China. Environmental Pollution, 214, 177-184. doi:10.1016/j.envpol.2016.04.012

7. Hartline, N. L., Bruce, N. J., Karba, S. N., Ruff, E. O., Sonar, S. U., \& Holden, P. A. (2016) Microfiber Masses Recovered from Conventional Machine Washing of New or Aged Garments. Environmental Science \& Technology, 50(21), 11532-11538. doi:10.1021/acs.est.6b03045

8. Suaria, G., Achtypi, A., Perold, V., Lee, J. R., Pierucci, A., Bornman, T. G., Ryan, P. G. (2020) Microfibers in oceanic surface waters: A global characterization. Science Advances, 6(23), eaay8493. doi:10.1126/sciadv.aay8493

9. Bomgardner, M. M. (2017) The great lint migration. C\&amp;EN Global Enterprise, 95(2), 16-17. doi:10.1021/cen-09502-bus1

10. Claessens, M., Van Cauwenberghe, L., Vandegehuchte, M. B., \& Janssen, C. R. (2013) New techniques for the detection of microplastics in sediments and field collected organisms. Marine Pollution Bulletin, 70(1-2), 227-233. doi:10.1016/j.marpolbul.2013.03.009

11. Gordon, M., Knauer, G. A., \& Martin, J. H. (1980) Mytilus californianus as a bioindicator of trace metal pollution: Variability and statistical considerations. Marine Pollution Bulletin, 11(7), 195-198. doi:10.1016/0025-326x(80)90492-0

12. Oehlmann, J., \& Schulte-Oehlmann, U. (2003) Chapter 17 Molluscs as bioindicators. Trace Metals and Other Contaminants in the Environment, 577-635. doi:10.1016/s0927-5215(03)80147-9

13. Salazar, M. H., \& Salazar, S. M. (1996) Mussels as Bioindicators: Effects of TBT on Survival, Bioaccumulation, and Growth under Natural Conditions. Organotin, 305-330. doi:10.1007/978-94-009-1507-7_15

14. Morris, R. H., Haderlie, E. C., \& Abbott, D. P. (1980) Intertidal invertebrates of California. Stanford, CA: Stanford Univ. Press.

15. Schmidt, D. (1997) A Review of California Mussel (Mytilus californianus), Fisheries Biology and Fisheries Program. Canada: Fisheries and Oceans.

16. De Kluijver, M. J., Ingalsuo, S. S., \& De Bruyne, R. H. (n.d.) Mollusca of the North Sea. Retrieved August 26, 2020, from bttp:// species-identification.org/species.php?species_group=mollusca

17. Li, J., Yang, D., Li, L., Jabeen, K., \& Shi, H. (2015) Microplastics in commercial bivalves from China. Environmental Pollution, 207, 190-195. doi:10.1016/j.enupol.2015.09.018

18. Hidalgo-Ruz, V., Gutow, L., Thompson, R. C., \& Thiel, M. (2012) Microplastics in the Marine Environment: A Review of the Methods Used for Identification and Quantification. Environmental Science \& Technology, 46(6), 3060-3075. doi:10.1021/es2031505

19. Smith, M., Love, D. C., Rochman, C. M., \& Neff, R. A. (2018) Microplastics in Seafood and the Implications for Human Health. Current Environmental Health Reports, 5(3), 375-386. doi:10.1007/s40572-018-0206-z.

20. Mathalon, A., \& Hill, P. (2014) Microplastic fibers in the intertidal ecosystem surrounding Halifax Harbor, Nova Scotia. Marine Pollution Bulletin, 81(1), 69-79. doi:10.1016/j.marpolbul.2014.02.018

21. U.S. Census Bureau. (2020) City and Town Population Totals: 2010-2019. Retrieved August 27, 2020, from https:// www.census.gov/data/tables/time-series/demo/popest/2010s-total-cities-and-towns.html

22. Davis, H. (2018, November 15) Newport settles claim over sewage spills into bay and other local waters. Retrieved August 26, 2020, from https:/ / www.latimes.com/socal/daily-pilot/ news/tn-dpt-me-sewage-settlement-20181114-story.html

23. Van Cauwenberghe, L., \& Janssen, C. R. (2014) Microplastics in bivalves cultured for human consumption. Environmental Pollution, 193, 65-70. doi:10.1016/j.envpol.2014.06.010

24. Behrens Yamada, S., \& Dunham, J. B. (1989) Mytilus californianus, a new aquaculture species? Aquaculture, 81(3-4), 275-284. doi:10.1016/0044-8486(89)90152-x

25. Von Moos, N., Burkhardt-Holm, P., \& Köhler, A. (2012) Uptake and Effects of Microplastics on Cells and Tissue of the Blue Mussel Mytilus edulis L. after an Experimental Exposure. Environmental Science \& Technology, 46(20), $11327-11335$. doi:10.1021/es302332w

26. Bergmann, M., Mützel, S., Primpke, S., Tekman, M. B., Trachsel, J., \& Gerdts, G. (2019) White and wonderful? Microplastics prevail in snow from the Alps to the Arctic. Science Advances, 5(8), eaax1157. doi:10.1126/sciadv.aax1157

27. Brahney, J., Hallerud, M., Heim, E., Hahnenberger, M., \& Sukumaran, S. (2020) Plastic rain in protected areas of the United States. Science Advances, 368(6496), 1257-1260. doi:10.1126/science.aaz5819 
28. Li, J., Lusher, A. L., Rotchell, J. M., Deudero, S., Turra, A., Bråte, I. L. N., Shi, H. (2019) Using mussel as a global bioindicator of coastal microplastic pollution. Environmental Pollution, 244, 522-533. doi:10.1016/j.envpol.2018.10.032

29. Cattaneo, B. (2018) How much fish do we consume? First global seafood consumption footprint published. Retrieved August 26, 2020, from bttps:// ec.europa.eu/jrc/ en/ news/ how-much-fish-do-we-consume-first-global-seafood-consumption-footprint-published

\section{ABOUT THE STUDENT AUTHOR}

Chloe Mankin graduated from California Lutheran University in August 2019 with a BS in Environmental Science. She is pursuing a master's degree in either environmental field research or resource management. Chloe hopes to use her degree to continue her work in the park services or conduct research in a lab setting.

\section{PRESS SUMMARY}

Microfibers are an emerging threat to aquatic habitats and human health worldwide. These microscopic pieces of plastic, typically defined as less than $5 \mathrm{~mm}$ in diameter, are a type of microplastic that originates from synthetic clothing, such as polyester and nylon. Often through the process of machine washing, fiber fragments are expelled into the wastewater and are eventually deposited into the environment. Filter feeder organisms, such as mussels, ingest these pollutants, and in turn, are consumed by other organisms, including humans. There has been little examination of the mussels located in the harbor, coastal beaches, and supermarkets of southern California. In this study, we quantified the number of microfibers ingested by mussels. We discovered microfibers in $99.98 \%$ of the mussels examined, indicating widespread microplastic pollution and uptake by mussels in these locations. 